\title{
VHL Gene Mutation Analysis of a Chinese Family with Non- Syndromic Pheochromocytomas and Patients with Apparently Sporadic Pheochromocytoma
}

\author{
Bin Zhang ${ }^{1}$, Jing Qian², De-Hui Chang ${ }^{1}$, Yang-Min Wang ${ }^{1 *}$, Da-Hai Zhou ${ }^{3}$, Gou- \\ Mei Qiao ${ }^{1}$
}

\begin{abstract}
Objective: The Von Hippel-Lindau syndrome (VHLD), an inherited neoplastic syndrome predisposing to central nervous system hemangioblastoma (CNS), pheochromocytoma (PCC), renal cell carcinoma(RCC), retinal hemangioma (RA) and renal cysts, is caused by mutations or deletions of the VHL tumor-suppressor gene. To assess VHL genotype-phenotype correlations with function of pVHL a gene mutation analysis of members in a Chinese family with non-syndromic PCCs and individuals with apparently sporadic pheochromocytoma (ASP) was performed. Materials and Methods: DNA samples of 20 members from the Chinese family with nonsyndromic PCCs and 41 patients with ASP were analyzed by polymerase chain reaction and direct sequencing, confirmed by Taqman probe. Results: Three novel mutations (H125P, 623(^TTTGTtG) and R120T) were identified in the Chinese family and in 3 among 41 ASP patients. The mutations were all located in exon 2 of VHL gene encoding $\beta$-domain of pVHL. The tumor type in H125P carriers and R120T carriers was VHL type 2C. And 623( ${ }^{\wedge}$ TTTGTtG) carriers presented VHL type 2B or type 2C. Conclusions: VHL gene abnormalities were identified in the Chinese family with non-syndromic PCCs and patients with APS, resulting in dysfunction of pVHL. H125P and R120T could be associated with VHL type 2C, while 623(^TTTGTtG) might be linked with VHL type $2 B$ or type 2C. Not only is the genetic analysis helpful for early diagnosis and treatment of patients with VHLD, it is also benefitial for research intoVHLD pathogenesis.
\end{abstract}

Keywords: von Hippel-Lindau syndrome - gene - mutation - pheochromocytomas - familial - sporadic

Asian Pac J Cancer Prev, 16 (5), 1977-1980

\section{Introduction}

VHL gene is a tumor suppressor gene mapped to chromosome locus 3p25-26, encoding two different protein VHL(pVHL30 and pVHL19) that regulates hypoxia-inducible genes, the fibronectin matrix assembly, and angiogenesis. pVHL19 with 160 amino acid protein is located in the nucleus, pVHL30 with 213 amino acid is expressed both in the nucleus and cytoplasm. The pVHL19 is similar to the pVHL30 in biochemistry and function, affecting a series of processes including cellcycle regulation, mRNA stability, hypoxia-induciblegene expression and transcription, etc (Lon ser et al., 2003).

The pVHL19 contains two functional subdomains: a smaller, helical $\alpha$-domain, which consists of three helices $(\mathrm{H} 1, \mathrm{H} 2$, and $\mathrm{H} 3$ ), and a larger $\beta$-domain(residues 63-154 and residues 193-204), which forms a seven-stranded $\beta$ sandwich and an $\alpha$ helix. These two subdomains contain different protein binding sites: The $\alpha$-subunit is connected to the elongin $\mathrm{C}$-binding site and the $\beta$-subunit binds to a region of HIF- $\alpha$ that regulates the expression of VEGF (Binderup et al., 2013). Under the conditions of hypoxic and dysfunctional of pVHL, the expression of HIF- $\alpha$ and VEGF may rise, which may promote tumor incidence and growth. VHL gene mutations is related to the pathogenesis of VHLD (Gao et al., 2013)

According to genotype and phenotype, VHLD can be divided into two types: Type I not with pheochromocytoma (PCC) and Type II with PC. According to whether patients have renal cysts and renal cell carcinoma (RCC), Type II patients are further divided into three sorts: type 2A with low risk of renal cysts and $\mathrm{RCC}$, type $2 \mathrm{~B}$ with high risk of renal cysts and RCC and type 2C with isolated PCC. The incidence of VHLD patients with PCC is about $10 \%$ to $34 \%$. Most of them have typical clinical presentation, but a few are asymptomatic (Jime'nez et al., 2006). The main causes of VHL type I are correlated with missense mutations and partial deletions, which cause parts of dysfunction or a complete defect of protein function. On the other hand, the causes of VHL type II are usually 
related to missense mutations affecting $\mathrm{pVHL}$ to connect to the binding sites. It was suggested by a report that the estimate of hereditary disease in apparently sporadic pheochromocytoma (SPA) was as high as $24 \%$ (Jime'nez et al., 2006).

Thus, some medical institutions recommend genetic testing for patients with VHLD and SPA (Ali Tootee and Shirin Hasani-Ranjbar., 2012; Bausch et al., 2013; Andreasson et al., 2013). In order to find the relationship between VHL gene mutation type and the tumor type, we carried out VHL gene detection in a Chinese family with non-syndromic PCCs and patients with ASP. And now we present the result of VHL gene analysis.

\section{Materials and Methods}

\section{Families with non-syndromic PCCs}

The family with PCCs includes 56 members of 4 generations, and is from Gansu Province. Among them, 7 extended over 3 generations were diagnosed as PCCs. One died before admission and another died due to a cardiovascular incident. Five were initially evaluated; evaluation included medical history, physical examination, abdominal ultrasonography, computed tomography (CT) or magnetic resonance imaging (MRI). Laboratory tests included routine biochemical testing, blood catecholamines and $24 \mathrm{~h}$ urinary catecholamine metabolite determination. The results showed that the levels of blood catecholamines and $24 \mathrm{~h}$ urinary vanillylmandelic acid were elevated significantly (more than 3 times).

All 5 patients (probands, see Table 1) underwent surgical resection. The tumors were benign under pathological examinations. There were no recurrence and malignant transformation over the period of up to 23-year follow-up. Twenty members, including 5 live patients and 15 direct relatives, accepted genetic examination.

\section{Patients with ASP}

Forty-one unrelated patients were selected from 91 with ASP who were registered in Urology Center of Lanzhou General Hospital, China, between 2005 and 2010, with the selection criteria (age below $60 \mathrm{yr}$, undertaking surgey resection and comfirmed by pathology). They all participated in preoperative evaluation, including medical history, physical examination, abdominal ultrasonography, CT or MRI, routine biochemical testing, blood catecholamines and $24 \mathrm{~h}$ urinary catecholamine metabolite determination. There were 17 males and 24 females (42.80 \pm 9.73 years in age); 15 cases had the left adrenal tumor, 24 cases with the right adrenal tumor, and 2 cases with bilateral adrenal tumors.

Materials and PCR: An informed consent was obtained from all participants. Genomic DNA analysis from peripheral blood leukocytes was conducted at the Urology Center of Lanzhou General Hospital, China for the 41 unrelated patients who underwent surgery for ASP and 20 members of the Chinese family. DNA extraction was performed by using D9081 kit (Takara Biotechnology, Dalian, China) according to the manufacturer's instruction. The three exons of the VHL gene were amplified and directly sequenced.
Primer sequences are available upon request. And the primers were synthesized by Takara.PCR amplification was carried out in $1 \times 1$ PCR buffer (Takara) that contained $400 \mathrm{~m} \mathrm{ol} /$ liter deoxynucleotide triphosphate, $0.4 \mathrm{~mol} / \mathrm{liter}$ of each primer, 2.5 units of Taq polymerase (Takara), and 100-200ng of DNA template in a $50 \mu$ l volume. PCR conditions: one cycle of $15 \mathrm{~min}$ at $95^{\circ} \mathrm{C} ; 30$ cycles of $45 \mathrm{~s}$ at $95^{\circ} \mathrm{C} ; 45 \mathrm{~s}$ at $63^{\circ} \mathrm{C} ; 45 \mathrm{~s}$ at $72^{\circ} \mathrm{C}$; followed by one cycle of $10 \mathrm{~min}$ at $72^{\circ} \mathrm{C}$ (Exon 1). one cycle of $15 \mathrm{~min}$ at $95^{\circ} \mathrm{C} ; 30$ cycles of $45 \mathrm{~s}$ at $95^{\circ} \mathrm{C} ; 45 \mathrm{~s}$ at $59^{\circ} \mathrm{C} ; 45 \mathrm{~s}$ at $72^{\circ} \mathrm{C}$; followed by one cycle of $10 \mathrm{~min}$ at $72^{\circ} \mathrm{C}($ Exon 2$)$; one cycle of 15 min at $95^{\circ} \mathrm{C} ; 30$ cycles of $45 \mathrm{~s}$ at $95^{\circ} \mathrm{C} ; 45 \mathrm{~s}$ at $57^{\circ} \mathrm{C} ; 45 \mathrm{~s}$ at $72^{\circ} \mathrm{C}$; followed by one cycle of $10 \mathrm{~min}$ at $72^{\circ} \mathrm{C}$ (Exon 3 ). The 7500 PCR System (Applied Biosystems, USA) was used for PCR reactions. The PCR products were performed sequence analysis by direct cycle sequencing using the Big Dye terminator v3.1 DNA Sequencing Kit (Applied Biosystems, USA) and an automated sequencer ABI PRISM 3730 (Applied Biosystems, USA). Mutations were confirmed by Taqman probe (the primers and probes were synthesized by Takara and checked by NCBI-BLAST).

\section{Results}

VHL gene mutations, including 2 missense mutations and 1 insertion mutation, were identified in all 20 members of the Chinese family ( 5 patients and 15 relatives) as well as all patients with ASP. In the family, a disease-causing heterozygous $\mathrm{H} 125 \mathrm{P}$ mutation was detected in the 5 probands with non-syndromic PCCs, whose onset age was between 8 and 20 .

There were some members of this family also had H125P mutation of the VHL gene, but this proved to be a neutral variant and the levels of blood catecholamines and $24 \mathrm{~h}$ urinary catecholamine metabolite were normal. One member (proband 1, male, 17 years old) was admitted to the hospital because of recurrent headaches, Palpitations, sweating and blurred vision of five month. Proband 1 had unilateral multiple PCCs. The carrier 1 (sister to proband 1) with bilateral PCCs, was accepted surgery, and the pathological result was benign. The presenting tumor types in probands and carriers from this family were non-symptomatic.

Out of the 41 unrelated patients with ASP, one patient had R120T missense mutation and 2 patients had 623 (^TTTGTtG) insertion mutations, respectively. The proband 6 carrying R120T missense mutation had unilateral renal cyst and hypertension, whose family screening showed the presence of the same mutation in her two healthy relatives (carrier 9 and carrier 10, see Table 1), but her mother (carrier 8) also had unilateral PCC, whose outcome of pathology was benign.

There were no newly developed VHL-related tumors on the carrier 11 and carrier 12 , carrying $623\left(^{\wedge}\right.$ TTTGTtG) mutations. The proband 8 with unilateral PCC had bilateral renal cysts. His mother (carrier 13) with unilateral PCC was asymptomatic, refusing to accept surgery. The family pedigrees and mutation sequencings table were presented in our early study (Andreasson et al., 2013; Zinnamosca et al., 2013). 
Table 1. Summary of Clinical Data and Mutation Analysis Results

\begin{tabular}{|c|c|c|c|c|c|c|}
\hline Patient & $\begin{array}{l}\text { gender } \\
\text { (age }\end{array}$ & $\begin{array}{l}\text { PCC } \\
\text { at first diagnosis,years }\end{array}$ & $\begin{array}{l}\text { Other clinical } \\
\text { s) presence }\end{array}$ & $\begin{array}{l}\text { VHLD } \\
\text { type }\end{array}$ & $\begin{array}{l}\text { Mutation } \\
\text { type }\end{array}$ & Mutation \\
\hline aProband 1 & Male & Uilateral multiple, 18 & & IIC & Missense & $\mathrm{H} 125 \mathrm{P}$ \\
\hline aCarriers1(sister to proband 1$)$ & Female & Bilateral,29 & & IIC & Missense & H125P \\
\hline${ }^{\mathrm{a} C a r r i e r s} 2($ nephew to proband 1$)$ & Male & & Asymptomatic & & Missense & $\mathrm{H} 125 \mathrm{P}$ \\
\hline${ }^{\text {aProband} 2}$ & Male & Bilateral,8 & & IIC & Missense & H125P \\
\hline aproband3 & Male & Bilateral,17 & & IIC & Missense & H125P \\
\hline${ }^{\mathrm{a}}$ Carriers3(son to proband 2) & Male & & Asymptomatic & & Missense & H125P \\
\hline aProband4 & Female & Bilateral,16 & & & Missense & $\mathrm{H} 125 \mathrm{P}$ \\
\hline 'Carriers4(father to Proband3 ) & Male & & Asymptomatic & & Missense & $\mathrm{H} 125 \mathrm{P}$ \\
\hline aCarriers5(brother2 to Proband3) & Male & & & IIC & Missense & $\mathrm{H} 125 \mathrm{P}$ \\
\hline aCarriers6(nephew to Proband3) & Male & & Asymptomatic & & Missense & $\mathrm{H} 125 \mathrm{P}$ \\
\hline aCarriers7(niece to Proband3) & Male & & Asymptomatic & & Missense & $\mathrm{H} 125 \mathrm{P}$ \\
\hline aProband5 & Male & Bilateral,16 & & IIC & Missense & $\mathrm{H} 125 \mathrm{P}$ \\
\hline bProband6 & Female & Unilateral,28 & & IIC & Missense & R120T \\
\hline bCarriers8(mother to Proband6) & Female & Unilateral,54 & & IIC & Missense & R120T \\
\hline 'Carriers9(aunt to Proband6) & Female & & Asymptomatic & & Missense & R120T \\
\hline${ }^{\mathrm{b}}$ Carriers 10 (cousin to aunt) & Female & & Asymptomatic & & Missense & R120T \\
\hline${ }^{\mathrm{b}}$ Proband7 & Male & Unilateral,22 & & IIC & Insertion & $623\left(^{\wedge} \mathrm{TTTGTtG}\right)$ \\
\hline${ }^{\mathrm{b}}$ Carriers11(father to Proband7) & Male & & Asymptomatic & & Insertion & $623\left(^{\wedge} \mathrm{TTTGTtG}\right)$ \\
\hline 'Carriers12(sister to Proband7) & Female & & Asymptomatic & & Insertion & $623\left({ }^{\wedge} \mathrm{TTTGTtG}\right)$ \\
\hline${ }^{\mathrm{b}}$ Proband 8 & Male & Unilateral,29 & Bilateral Renal cysts & IIB & Insertion & $623\left(^{\wedge} \mathrm{TTTGTtG}\right)$ \\
\hline${ }^{\mathrm{b}}$ Carriers13(mother to Proband7) & Female & Unilatera,50 & & IIC & Insertion & $623\left(^{\wedge} \mathrm{TTTGTtG}\right)$ \\
\hline
\end{tabular}

${ }^{\mathrm{a}}$ :members from a Chinese family with Non-syndromic PCCs; ${ }^{\mathrm{b}}$ :patients with ASP

\section{Discussion}

In the present study, we reported that genetic abnormal origin of VHLD in members from the Chinese family with non-syndromic PCCs and in 3 of 41 patients with ASP $(7.3 \%)$. We detected 3 disease-causing novel genetic mutations, included 2 missense mutations (H125P and $\mathrm{R} 120 \mathrm{~T})$ and an insertion mutation (623( $\left.{ }^{\wedge} \mathrm{TTTGTtG}\right)$ ), located in exon 2 encoding $\beta$-domain of pVHL. Mutations resulted in dysfunction $\mathrm{pVHL}$ and were associated mainly with VHL type 2 B or type 2 C. Some VHL mutations of $\mathrm{RCC}$ have been reported in Chinese studies (Zinnamosca et al.,2013; Kim et al., 2013; Qi et al.,2013; Mete et al., 2013; Chen et al., 2013). These mutations in VHL patients differ from those observed in domestic VHLD kindreds. The reports about missense mutations and insertion mutations in Chinese with VHLD are first to report (Zhou et al., 2007; Zhang et al., 2009).

The frequency of PCC in VHLD patients was about $25 \%$. But the penetrance in members from the Chinese family in association with $\mathrm{H} 125 \mathrm{P}(12.5 \%)$ was lower than the other familial pheochromocytomas (Lanikova et al., 2013). The penetrance in patients with ASP $(7.3 \%)$ was similar to the figure observed in Western, Japanese, and Chinese VHLD kindreds (Tootee and Hasani-Ranjbar,2012; Vaganovs et al., 2013; King and Pacak, 2013). The age of tumor onset was between 5 and 20 associated with H125P. And most patients with H125P were with bilateral PCCs. The age of tumor presentation was between 22 and 54 associated with R120T and 623(^ ${ }^{\wedge}$ TTTGT tG). The patients with R120T and $623\left(^{\wedge}\right.$ TTTGTtG) had unilateral PCC. There were similar results of biochemical testing in patients with mutations, of which the levels of blood catecholamine and $24 \mathrm{~h}$ urinary catecholamine metabolite were all increased significantly (compared with normal level). We also tested healthy members and found that the mutations were absent in all clinical healthy members from the Chinese family who participated genetic screening and some direct relatives of patients with ASP. Limited participation in genetic evaluation among carriers and their relatives who have no abnormal clinical findings limited our ability to detect genetic modifiers and environmental factors.

According to guidelines from JCEM of 2006, genetic examinations for ASP are recommended for individuals with familiar history of PCCs especially for those of which a family member was diagnosed with PCCs under the age of 20 years, the PCCs were bilateral or in case of an extra-adrenal pheochromocytoma with catecholamine synthesis. Evidence indicates. Testings play an important role in medical management, such as timely diagnosis of non-syndromic PCCs, accurate genetic counseling and predictive testing, tumor resection, postoperative care, and close follow-up based on gene-specific clinical protocols. For the purposes of genetic counseling and genetic screeing, we need to underscore the importance of several demographic and clinical features associated with the presence of a germ line mutation, including age at diagnosis, multifocal disease, extra-adrenal location, and malignant tumors. According to the present study and reference, individuals whose age at onset were less than 50 years and had a family history, non-syndromic suspected pheochromocytoma, ganglion cell tumor syndrome group and pheochromocytoma, should accept VHL gene detecting. These individuals and their relatives could benefit from genetic detecting technology immediately.

As the sequencing technology progresses, genetic testing cost is decreasing. According to our method, the cost for searching for VHL mutations (covering 3 exons) by sequencing is 216 (RMB yuan), including DNA 
Bin Zhang et al

extraction and PCR-sequencing of each exon on DNA strands. Our goal in further research is to find new lab tech that is more sensitive with low cost and more cases of mutations will be found.

In conclusion, in our study we identified the VHL gene mutations (H125P, 623(^TTTGTtG) and R120T) in all individuals with PCCs who are members of a single Chinese family as well as three patients with APS in a cohort of 41 . These mutations resulted in dysfunction of pVHL. The genetic analysis is helpful for medical management of patients with HVLD or ASP and exploration of VHLD pathogenesis .

\section{Acknowledgements}

We thank Dr. Ha Xiao-qin and her team for the helpful advice and excellent technical assistance.

\section{References}

Ali Tootee, Hasani-Ranjbar S (2012). Von hippel-lindau disease: a new approach to an old problem. Int J Endocrinol Metab, 4, 619-24.

Andreasson A, Kiss NB, Caramuta S, et al (2013). The VHL gene is epigenetically inactivated in pheochromocytomas and abdominal paragangliomas. Epigenetics, 12, 1347-54.

Bausch B, Wellner U, Bausch D, et al (2013). Long-term prognosis of patients with pediatric pheochromocytoma. Endocr Relat Cancer, 1, 17-25.

Binderup ML, Bisgaard ML, Harbud V, et al (2013). Von hippellindau disease (VHL). Dan Med J, 12, 4763.

Chen J, Geng W, Zhao Y, Zhao H, et al (2013). Clinical and mutation analysis of four Chinese families with von HippelLindau disease. Clin Transl Oncol, 5, 391-7.

GAO Yong, HUANG Yan-ping, TU Xiang-an, et al (2013). Genetic characterization and protein stability analysis of a Chinese family with von hippel-lindau disease. Chin Med $J, 19,3690-93$.

Jime'nez C, Cote G, Arnold A,et al (2006). Review: should patients with apparently sporadic pheochromoeytomas or paragangliomas be screened for hereditary syndromes. $J$ Chn Endocrinol Metab, 8, 2851-58.

Kim J, Seong MW, Lee K, et al (2013). Germline mutations and genotype-phenotype correlations in patients with apparently sporadic pheochromocytoma/paraganglioma in Korea. Clin Genet, 5, 482-6.

King KS, Pacak K (2013). Familial pheochromocytomas and paragangliomas. Mol Cell Endocrinol, 1-2, 92-100.

Lanikova L, Lorenzo F, Yang C, et al (2013). Novel homozygous VHL mutation in exon 2 is associated with congenital polycythemia but not with cancer. Blood, 19, 3918-24.

Lon ser RR, G lenn GM, W altherM, et al (2003). von-Hippel Lindau disease. Lancet, 9374, 2059-67.

Mete T, Berker D, Yilmaz E, et al (2013). Clinical presentation of Von Hippel Lindau syndrome type 2B associated with VHL. Endocrine, 1, 128-35.

Qi XP, Liu WT, Li JY, et al (2013). p.N78S and $p . \mathrm{R} 161 \mathrm{Q}$ germline mutations of the VHL gene are present in von Hippel-Lindau syndrome in two pedigrees. Mol Med Rep, 3, 799-805.

Vaganovs P, Bokums K, Miklasevics E, et al (2013). Von hippel-lindau syndrome: diagnosis and management of hemangioblastoma and pheochromocytoma. Case Rep Urol, 2013, 624096.

Zhang B, Wang YM, Wang N, Ha XQ, et al (2009). Genetic detection and analysis of the VHL gene in patients with sporadic pheochromocytoma. Chin J Oncol, 5, 361-5.

Zhou DH, Wang YM, Lan T, et al (2007). Mutation screening of VHL gene in a Chinese family with non-syndromic pheochromocytoma. Chin J Med Genet, 4, 365-68.

Zinnamosca L, Laudisi A, Petramala L, et al (2013). Von Hippel Lindau disease with colon adenocarcinoma, renal cell carcinoma and adrenal pheochromocytoma. Intern Med, 14, 1599-603. 